\title{
Circulation of Journals
}

The following journals are available at the Library:

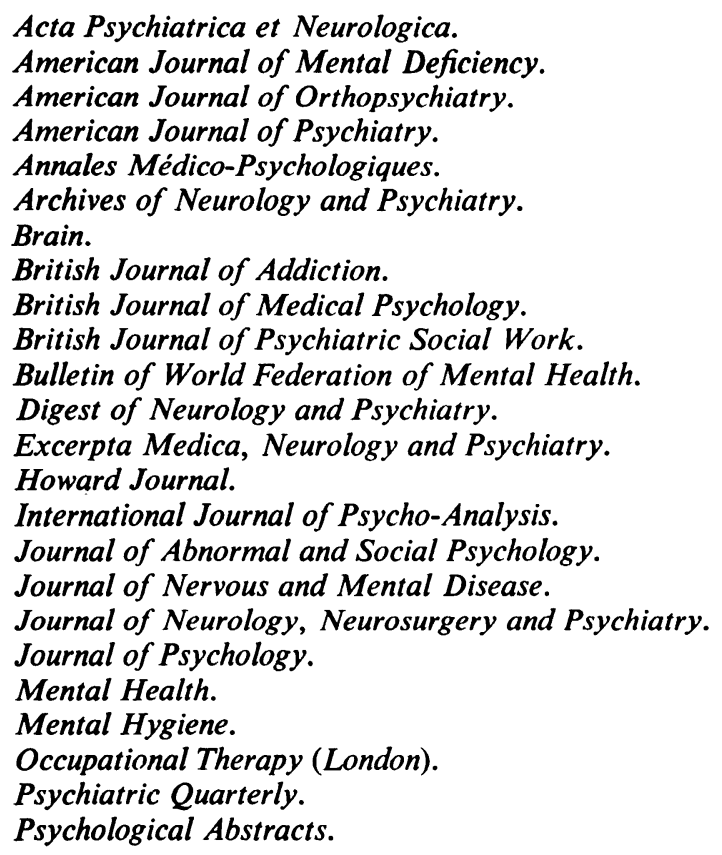

\section{NOTICES BY THE REGISTRAR}

\section{The Diploma in Psychological Medicine}

The examination for the Association's Diploma in Psychological Medicine will be held annually in May and November. The examination comprises:

Part I

(a) Psychology.

(b) Anatomy and Physiology in their relation to nervous and mental diseases.

Part II (a) Psychiatry.

(b) Psychosomatic Medicine and Neurology.

Fees are eight guineas for Part I and twelve guineas for Part II, and are payable to the Registrar, R.M.P.A.

Prospective candidates should apply to the Registrar at least two months before the examination at which they wish to sit.

Full particulars may be obtained from the Registrar, R.M.P.A., 11 Chandos Street, London, W.1, on receipt of stamped, addressed envelope.

\section{THE ASSOCIATION'S MEDALS AND PRIZES, 1954}

Attention is specially drawn to the Medals and Prizes which are offered annually by the Association: The conditions of award are set out fully in the Year-Book. 